\title{
Biomaterials from beer manufacture waste for bone growth scaffolds
}

\author{
M.A. Martin-Luengo ${ }^{\mathrm{a} *}$, M. Yates ${ }^{\mathrm{b}}$, M. Ramos ${ }^{\mathrm{c}}$, E. Saez Rojo ${ }^{\mathrm{a}, \mathrm{b}}$, A.M. Martinez Serrano ${ }^{\mathrm{a}, \mathrm{b}, \mathrm{c}}$, \\ L. Gonzalez Gil ${ }^{\mathrm{a}, \mathrm{b}}$ and E. Ruiz Hitzky \\ "Institute of Materials Science of Madrid (CSIC), Calle Sor Juana Ines de la Cruz 3, Cantoblanco, 28049 Madrid, Spain; \\ ${ }^{b}$ Institute of Catalysis and Petroleochemistry (CSIC), Calle Marie Curie 2, Cantoblanco, 28049 Madrid, Spain; "Centre of \\ Molecular Biology Severo Ochoa (CBMSO), Calle Nicolas Cabrera 1, Cantoblanco, 28049 Madrid, Spain
}

\begin{abstract}
Agricultural wastes are a source of renewable raw materials (RRM), with structures that can be tailored for the use envisaged. Here, they have proved to be good replacement candidates for use as biomaterials for the growth of osteoblasts in bone replacement therapies. Their preparation is more cost effective than that of materials presently in use with the added bonus of converting a low-cost waste into a value-added product. Due to their origin these solids are ecomaterials.

In this study, several techniques, including X-ray diffraction (XRD), chemical analysis, mercury intrusion porosimetry (MIP), scanning electron microscopy (SEM), and bioassays, were used to compare the biocompatibility and cell growth of scaffolds produced from beer bagasse, a waste material from beer production, with a control sample used in bone and dental regenerative processes.
\end{abstract}

Keywords: renewable raw materials (RRM); ecomaterials; bone; waste; scaffolds; bone growth; value added waste; green chemistry

\section{Introduction}

Following a reduction in the price of raw materials during the last two decades of the twentieth century, the present increase is causing serious damage to the world economy $(1-3)$. One solution for this is the use of so-called renewable raw materials (RRM), which are those derived from the agricultural and forestry sectors and used for purposes other than nutritional. RRM may be considered as valuable sources of materials for a number of chemical processes, sometimes with the added bonus of transforming potentially toxic wastes into value-added products $(4-6)$. Although energy production from biomass is well established, the use of agricultural waste to provide RRM for more advanced applications is now being seriously considered (7-9).

Bone and tooth replacement require materials that act as scaffolds, directing tissue formation and allowing the transport of biological nutrients. These materials, which require tailored porosity, surface chemistry, and mechanical strength, are typically produced from animal bone, organic oil-derived polymers, inorganic materials, or complex mixtures of all the above (10).

To prepare synthetic scaffolds several steps are necessary, i.e. precipitation of calcium-containing salts at constant $\mathrm{pH}$ and temperature; addition of hydroxides and phosphates, matured for different periods of time; filtration; drying; and subsequent calcination at very high temperatures, usually more than $900^{\circ} \mathrm{C}$, to provide the appropriate textures $(3,11)$. Another way to produce macroporous bioceramics is to fuse together calcium-containing precursors and polymers of controlled particle sizes to generate interconnected macroporosity when calcined to remove the organic matter (12-14).

In the past, natural materials have been assessed as replacement candidates for synthetic biomaterial scaffolds. For example, coral has been found to be an interesting natural substitute; according to the investigators, "the tissue-engineered bone of seeded natural coral-implant composite scaffold is promising for dental implant anchoring, which has positive implication for clinical jaw reconstruction" (15). However, this material is non-renewable, and its use can seriously damage the local environment, both flora and fauna, from whence it is removed (16).

The use of industrial wastes has been recognized as a source of RRM, value-added substances that may lead to a significant reduction (ideally $100 \%$ ) in waste (4-6). With the aim to convert waste into value-added 
products, agricultural wastes from several crops are at present being investigated by the authors as potential RRM for advanced applications, such as liquid subproducts from citrus production being employed instead of petroleum derivatives to obtain fine chemicals (4 6). In this study, beer bagasse, a low-cost waste material from beer production, was employed as the RRM that was tailored for use as biocompatible scaffolds for osteoblast growth, given its structure and composition (7-9). To the best of our knowledge this is the first time that agricultural waste has been modified to produce solids that can act as scaffolds for tissue regeneration.

\section{Results}

Chemical analysis of the RRM developed here from processing of low-cost natural waste products from beer production shows silicon (16\%), phosphorous $(12 \%)$, magnesium $(8 \%)$, calcium $(9 \%)$, potassium $(1.2 \%)$, iron $(0.2 \%)$, and aluminum $(0.1 \%)$ with traces of sodium and sulfur, all of which are biocompatible ions. In the human body calcium is used for muscle, bone, and digestive system functions; magnesium is required for processing ATP, and it builds bone and influences alkalinity; phosphorous is required for bones and body energy processing; and potassium and sodium are required electrolytes for the heart and nerves. Due to the origin of this waste material, this RRM can be considered as an ecomaterial $(7-9,17,18)$.

The structural characterisations of the RRM presented in Figure 1, using scanning electron microscopy, mercury intrusion porosimetry, and X-ray diffraction, shows the porous nature of the inorganic skeleton left after different pretreatments and subsequent calcination of the raw material (Figure 1a and b). From these two figures the presence of very wide pores due to both interparticulate and intraparticulate porosity is confirmed, with more than $90 \%$ of the porous structure being in pores greater than $80 \mu \mathrm{m}$. The bulk and skeletal densities of BBM 28 were 0.21 and 1.72 and of BBM47 were 0.20 and 1.63 , giving porosities of $87.5 \%$ and $88.0 \%$, respectively.

Previous studies carried out on materials with similar compositions reveal significant osseous growth when the pore sizes are within this range (19). The $\mathrm{X}$-ray diffraction patterns of these materials (Figure 1c) show peaks at $22,31,33$, and $34.52 \Theta$ corresponding to tricalcium phosphate (PDF 09-0348), $31.62 \Theta$ hydroxyapatite, and calcium silicate at $29.52 \Theta$ (PDF 01-1029), all of which are materials used for bone growth (20).

In Figure 2 the biocompatibility and efficiency for bone growth of these solids and a commercial synthetic scaffold was confirmed. Assuming 100\% as the rate of cell adhesion for the commercial material, those for BB47 and BB28 were found to be $110 \% \pm 12.6$ and $116 \% \pm 6.9$, respectively. Thus, confirming similar adhesion rates for the studied materials, demonstrating that they possess an appropriate porosity to allow cell adhesion. Calculating the percentage of live cells over total cells (live cells plus dead cells), a high cell viability rate is observed for both scaffold materials produced from RRM, similar to that of the commercial product and the control cell culture TCPS plates (Figure 2). Although BB28 had slightly reduced cell viability at initial time points, more than $85 \%$ of the cells growing on this material remained viable over the whole evaluation period. Since bone formation is a lengthy process, the most relevant aspect is that even after seven days of culture, both these materials displayed similar biocompatibilities and cell proliferation rates to those observed on the commercial sample and the TCPS. Figure 2(b) shows high percentages of live cells growing on the four materials studied in culture. This is evident by the predominance of green (live) over red (dead) cells growing on BB47 (A), BB28 (B), and Commercial (C), which indeed show a similar cell morphology to that observed on cells growing on TCPS (D). Thus, the results in regard to cell viability demonstrate similar ability of the osteoblast-like cell line to survive on the tested materials, with BB47 being the best to achieve maximum cell viability.

In summary, murine-derived osteoblastic cells (MC3T3-E1) actively adhere to the RRM studied here, with no significant changes in cell viability of cells growing on the RRMs compared to those observed with either the commercial material or the cells seeded directly onto TCPS plates. Such characteristics are desired in dental and orthopaedic prostheses (21). We conclude that our RRM are scaffolds that have the right characteristics to support adhesion and survival of the osteoblastic cell line MC3T3E1, strongly suggesting that they could be employed in oral and/or bone tissue regeneration. To the best of our knowledge this is the first time that an agricultural waste has been tailored to produce solids that can act as scaffolds for tissue regeneration.

\section{Experimental}

The beer bagasse as provided by a Spanish beer manufacturer was treated as indicated in the patent procedure (15). First, the solid was dried by heating in air from room temperature to $150^{\circ} \mathrm{C}$ at a heating rate of $5 \% \mathrm{~min}$, and this temperature was maintained for $4 \mathrm{~h}$ to stop any further fermentation of the waste, due to its rich nutrient content. A wide range of 
(a)

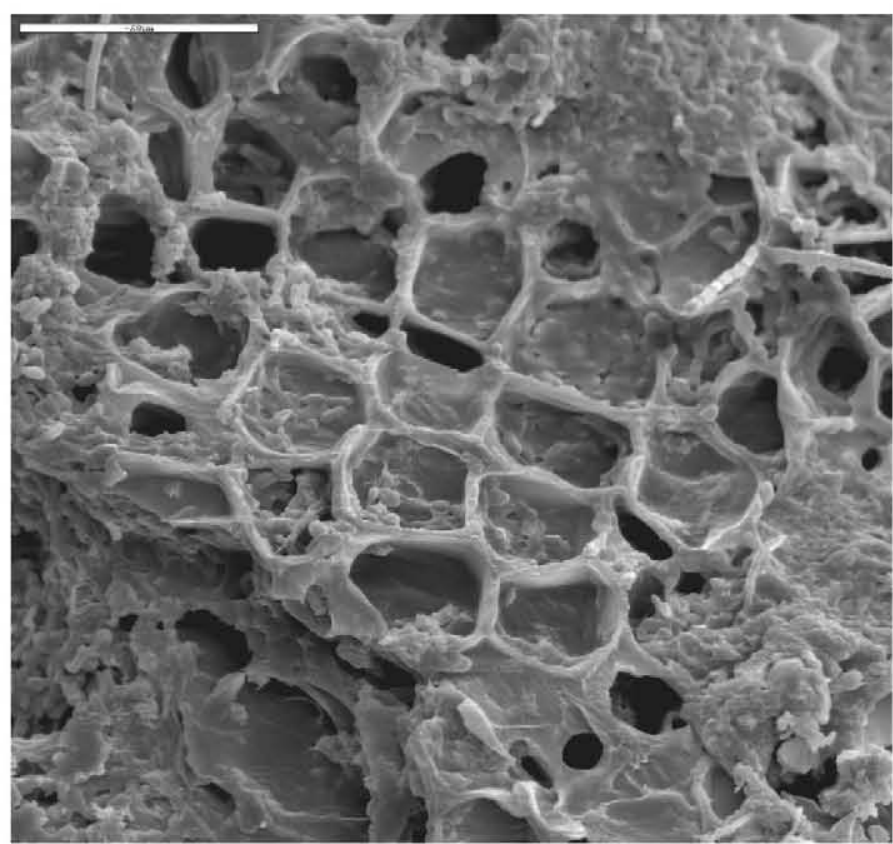

(b)

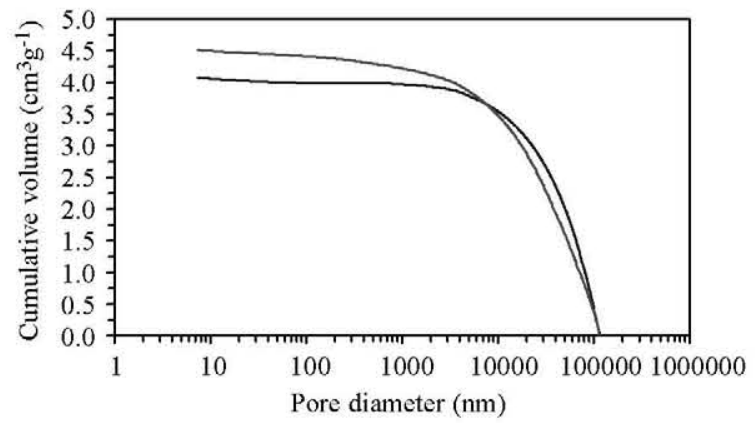

(c)

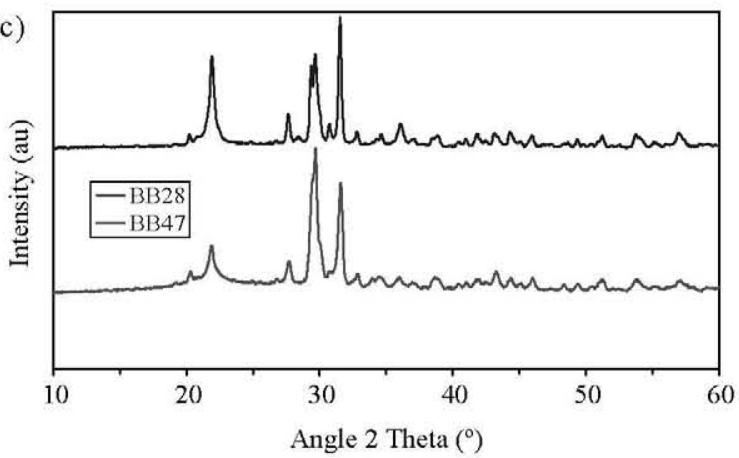

Figure 1. (a) Scanning electron micrograph of BB28. (b) Mercury intrusion porosimetry curves for BB28 (blue) and BB47 (red). (c) X-ray diffraction patterns for BB28 (blue) and BB47 (red).

thermal and chemical treatments were assessed in order to vary the structural and surface characteristics of the solids obtained.

Mercury intrusion porosimetry analyses were employed to determine the pore size distributions, pore volumes, particle size distributions, densities, and total porosities for the commercial material and the materials prepared from beer bagasse, utilizing CE Instruments Pascal 140/240 apparatus. The pressure/volume data were analyzed assuming a cylindrical non-intersecting pore model, taking the mercury contact angle as $141^{\circ}$ and surface tension as $484 \mathrm{~m} \mathrm{~N} \mathrm{~m}^{-1}$. All of the analyses were carried out on samples that had been previously dried at $150^{\circ} \mathrm{C}$ overnight to ensure the reproducibility of the results.

The chemical analyses of the composition of the solids were carried out by X-ray fluorescence spectroscopy using an EXTRA-II spectrometer Rich \& Seifert, with a xenon arc lamp of $150 \mathrm{~W}$. The working range is $200-900 \mathrm{~nm}$ with a wavelength accuracy of $\pm 0.5 \mathrm{~nm}$ and a scan speed of $160 \mathrm{~nm} / \mathrm{s}$, using a photodiode as a reference detector.

XRD analyses were carried out on a Seifert XRD $3000 \mathrm{P}$ model, recording the spectra in the range $2 \theta=$ $5-90^{\circ}$, with a step of $0.02^{\circ}$ and a $2 \mathrm{sec} /$ pass acquisition time. Micrographs of selected solids were taken in a scanning electron microscope ISI model DS$130 \mathrm{C}(40 \mathrm{kV})$.

To study cell adhesion to the materials, the biocompatibility and efficiency for bone growth, MC3T3-E1, an osteoblast-like cell line, was chosen because they are well characterized for modeling endogenous osteoblasts (16). A commercial synthetic scaffold, hydroxyapatite nanopowder $(<200 \mathrm{~nm})$ from Sigma Aldrich, was used for comparison.

The cells were seeded onto material-coated plates in DMEM-10\%FBS and allowed to adhere for $2 \mathrm{~h}$ at $37^{\circ} \mathrm{C}$ in a $5 \% \quad \mathrm{CO}_{2}$ atmosphere. Plates were then 


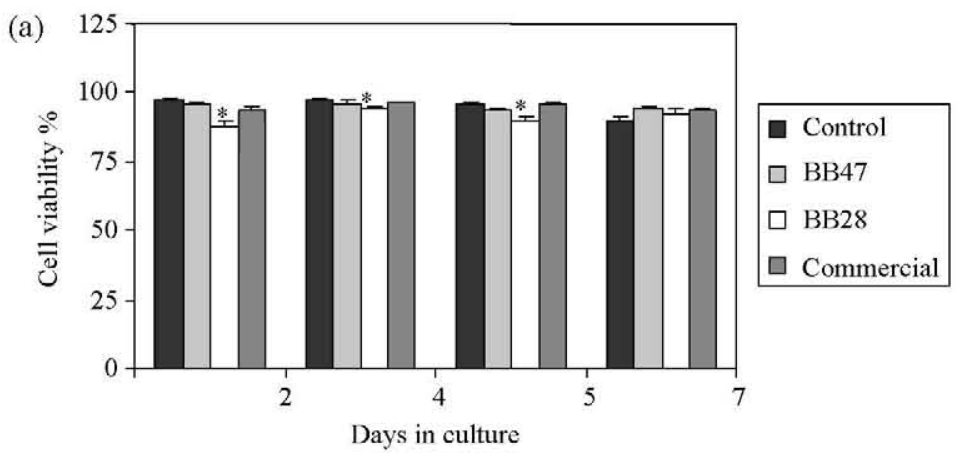

(b)
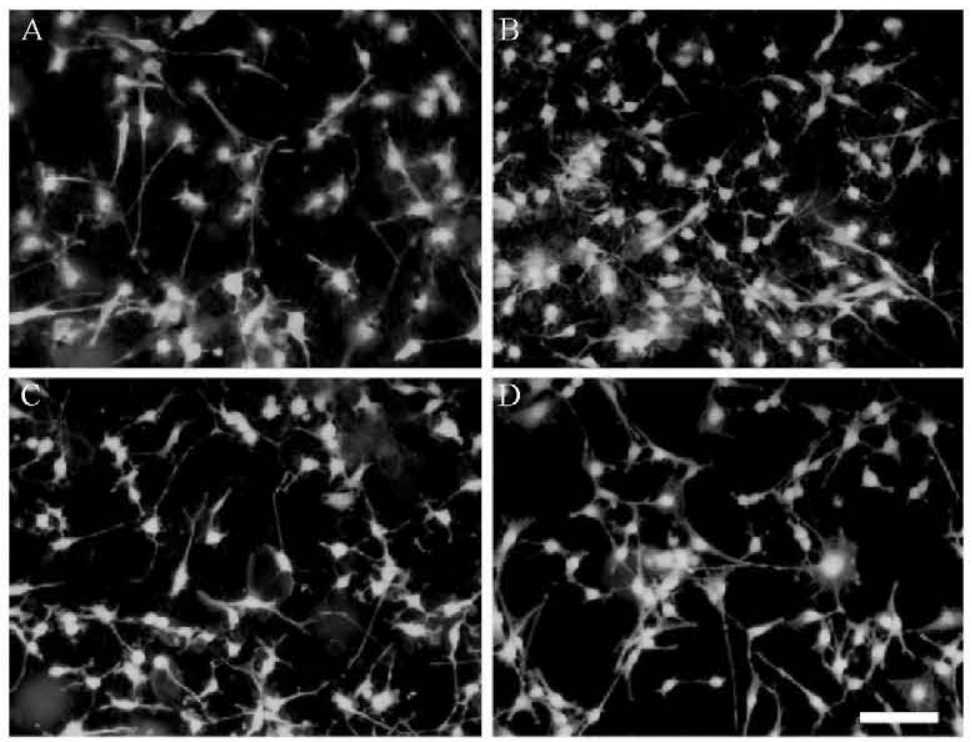

Figure 2. (a) MC3T3-E1 cell viability after 2, 4, 5, and 7 days growing on TCPS plates or on plates coated with BB28, BB47, or Commercial. Cell viability was evaluated by live/dead viability assay kit. Data represent mean \pm S.E.M. of three independent experiments. ( $p<0.05$, ANOVA, post-hoc Tukey HSD test, * vs. Control). (b) MC3T3-E1 cells were seeded on tissue culture plates coated with BB47 (A), BB28 (B), Commercial (C), and TCPS control plates (D) for 4 days. Live/Dead Viability Assay Kit was used to determine the cell viability (red: dead cells; green: live cells) (colour online). Scale bar $100 \mu \mathrm{m}$.

washed with phosphate-buffered based saline solution (PBS) to remove non-adherent cells. Adherent live cells were quantified using the live/dead viability assay kit (Molecular Probes) (22). The number of live adhered cells was evaluated by fluorescence microscopy, counting at least 10 representative fields per well.

The biocompatibility of the materials was assessed with the same MC3T3-E1 cells after different periods of exposition, comparing the results to those obtained with the commercial material and regular tissue culture polystyrene (TCPS) plates, used as controls. The viability of MC3T3-E1 cells growing on TCPS, BB47, BB28, and the commercial material was determined at two, four, five, and seven days by the live/dead viability assay, to distinguish dead cells (red) from live ones (green), as observed by inverted fluorescence microscopy (23).

\section{Acknowledgements}

This work has been supported by the CICYT (Spain; Projects: BTE2003-05757-CO2-O2, MAT2006-03356, MAT2009-09960) and the Comunidad de Madrid (Spain; Project S-0505/MAT/000227).

\section{References}

(1) Poliakoff, M.; Fitzpatrick, J.M.; Farren, T.R.; Anastas, P.T. Green Chemistry: Science and Politics of Change. Science 2002, 297, 807-810.

(2) Manley, J.B.; Anastas, P.T.; Cue, B.W., Jr. Frontiers in Green Chemistry: Meeting the Grand Challenges for Sustainability in R\&D and Manufacturing. J. Cleaner Prod. 2008, 16 (6), 743-750.

(3) Ragauskas, A.J.; Williams, C.K.; Davison, B.H.; Britovsek, G.; Cairney, J.; Eckert, C.A.; Frederick, W..J., Jr.; Hallett, J.P.; Leak, D.J.; Liotta, C.L.; Mielenz, J.R.; Murphy, R.; Templer, R.; Tschaplinski, T. The 
Path Forward for Biofuels and Biomaterials. Science 2006, 311, 484-489.

(4) Symposium on "Renewable Raw Materials for Industry: Contribution to Sustainable Chemistry," 2007, Belgium.

(5) Martin-Luengo, M.A.; Yates, M.; Casal, B.; Martinez Domingo, M.J.; Esteban, M.; Ruiz Hitzky, E. Synthesis of $p$-Cymene from Limonene, a Renewable Feedstock. Appl. Catal., B 2008, 81, 218-225.

(6) Martin-Luengo, M.A.; Yates, M.; Saez Rojo, E.; Huerta Arribas, D.; Aguilar, D.; Ruiz Hitzky, E. Sustainable $p$-Cymene and Hydrogen from Limonene. Appl. Catal., A 2010, 387 (1-2), 141-146.

(7) Harish Prashanth, K.V.; Tharanathan, R.N. Chitin/ Chitosan: Modifications and Their Unlimited Application Potential an Overview. Trends Food Sci. Technol. 2007, 18, 117-126.

(8) Al Seadi, T.; Holm-Nielsen, B. III. 2 Agricultural Wastes. Waste Management Series 2004, 4, 207-215.

(9) Martin Luengo, M.A.; Yates, M.; Casal, B. Preparation of Biocompatible Materials from Beer Production and Their Uses. Spanish patent PCT/ES2009/070475.

(10) Cao, H.; Kuboyama, N. A Biodegradable Porous Composite Scaffold of PGA/ $\beta$-TCP for Bone Tissue Engineering. Bone 2010, 46, 386-395.

(11) Hench, L.L.; Polar, J.M. Third-Generation Biomedical Materials. Science 2002, 295, 1014-1017.

(12) Descamps, M.; Richart, O.; Hardouin, P.; Hornez, J.C.; Leriche, A. Synthesis of Macroporous $\beta$-Tricalcium Phosphate with Controlled Porous Architectural. Ceram. Int. 2008, 34, 1131-1137.

(13) Veis, A. A Window on Biomineralization. Science 2005, 307 (5714), 1419-1420.

(14) Kim, S.; Kim, S.-S.; Lee, S.H.; Eun Ahn, S.; Gwak, S.J.; Chung, H.-M. In vivo Bone Formation from Human Embryonic Stem Cell-Derived Osteogenic Cells in Poly(d,1-lactic-co-glycolic acid)/Hydroxyapatite Composite Scaffolds. Biomaterials 2008, 29, 1043 1149 .
(15) Petite, H.; Viateau, V.; Bensaid, W.; Meunier, A.; de Pollak, C.; Bourguignon, M.; Oudina, K.; Sedel, L.; Guillemin, G. Tissue-Engineered Bone Regeneration. Nat. Biotechnol. 2000, 18, 959-963.

(16) Chen, F.; Ouyang, H.; Feng, X.; Gao, Z.; Yang, Y.; Zou, X.; Liu, T.; Zhao, G.; Mao, T. Anchoring Dental Implant in Tissue-Engineered Bone Using Composite Scaffold: A Preliminary Study in Nude Mouse Model. J. Oral Maxillofac. Surg. 2005, 63, 586-595.

(17) Halada, K. Progress of Ecomaterials toward a Sustainable Society. Curr. Opin Solid State Mater. Sci. 2003, 7, 209-216.

(18) Ben-Nissan, B. Natural Bioceramics: From Coral to Bone and Beyond. Curr. Opin. Solid State Mater. Sci. 2003, 7, 283-288.

(19) Murphy, C.M.; Haugh, M.G.; O'Brien, F.J. The Effect of Mean Pore Size on Cell Attachment, Proliferation and Migration in Collagen-glycosaminoglycan Scaffolds for Bone Tissue Engineering. Biomaterials 2010, 31 (3), 461-466.

(20) Tadic, D.; Epple, M. A Thorough Physicochemical Characterisation of 14 Calcium Phosphate-Based Bone Substitution Materials in Comparison to Natural Bone. Biomaterials 2004, 25, 987-995.

(21) Bertazzo, S.; Zambuzzi, W.F.; da Silva, H.A.; Ferreira, C.V.; Bertran, C.A. Bioactivation of Alumina by Surface Modification: A Possibility for Improving the Applicability of Alumina in Bone and Oral Repair. Clin. Oral Implants Res. 2009, 20 (3), 288-293.

(22) Simon, C.G.; Guthrie, W.F.; Wang, F.W. Cell Seeding into Calcium Phosphate Cement. J. Biomed. Mater. Res. Part A 2004, 68A (4), 628-639.

(23) Chou, Y.F.; Huang, W.; Dunn, J.C.; Miller, T.A.; Wu, B.M. The Effect of Biomimetic Apatite Structure on Osteoblast Viability, Proliferation, and Gene Expression. Biomaterials 2005, 26, 285-295. 